\title{
MENTAL WORKLOAD ANALYSIS OF NAVAL CADET ACADEMY USING SUBJECTIVE WORKLOAD ASSESSMENT TECHNIQUE (SWAT) METHODS
}

\author{
Elisabeth Tanti Pudiastuti \\ Sekolah Tinggi Manajemen STIMA IMMI Jakarta Indonesia \\ Email : ibeth7210@gmail.com
}

\begin{abstract}
There are plentiful activities conducted by the Cadets in order to hold educational process at the Naval Academy. These activities are particularly vulnerable to physical and psychological friction, especially in routine and nurturing activities, where activities in this phase are thought to cause the Cadets to experience excessive mental workloads which may result in the Cadets being unable to continue their education. Therefore, this research would identify one of the factors that were suspected to be the cause of the problem which was psychological factor or mental workload on the Academy of Naval using Subjective Workload Asessesment Technique (SWAT) method. SWAT method was chosen because it was easier to apply and had some advantages in terms of results validity and accuracy, so that the performance of Cadets expected by Institution were: Tanggap, Tanggon and Trengginas. The results of this study indicated that there was a high mental workload for some sub activities at some level. The highest mental workload in level I is 69,0 (RPS activity), in level II is 83,4 (senior junior development), in level III is 77,6 (senior junior development). Besides this research also showed that the mental workload between the four levels of Level I, II, III and IV had a significant difference in mental workload in carrying out every activity at the Academy.
\end{abstract}

Keywords: Subjective Workload Assessment Technique (SWAT), Mental Workload, Cadets.

\section{INTRODUCTION}

The education methods applied in the Naval Academy are teaching, training and nurturing methods (Yudhoyono \& Jalal, 2009/2010). The aims of the methods are described as follows: Teaching method aims to equip Cadets with general science and basic profession as marine warriors. The training method aims to equip the Cadets with the basic skills of the profession as well as the special profession of each corps. Nurturing aims to shape, nurture and solidify the personality of Cadets and the spirit of true warrior (W.Masland \& Radway, 2015).

Various activities are conducted by the Cadets in the education process in Naval Academy. Each Cadets activity will provide workload in the form of physical workload or mental workload. The most dominant workload wich has a high stress buren is the mental workload, thus the metal workload must be considered. In addition, the activities of Cadets are very susceptible to physical and psychological friction, especially in routine and nurturing activities, where activities in this phase are expected to cause the Cadets to experience excessive mental workload which may cause the Cadets to not continue their education. Based on data obtained from the Cadets Regiment recorded during the period of 6 years (2008-2013), there were 17 Cadets expelled, whether it was due to mental factors or due to other factors.

Based on those data, it can be said that there are still very serious problems in the educational environment, why is that? In an education, the number of incoming education will be equal to the number that graduated, because the Cadets who follow the education are those who have been through a variety of selection that is so tight both at the regional and central levels. Among thousands of people who register, the number of people accepted are only \pm 100 people each generation or \pm 1:20 in each enrollment, meaning that the person accepted is a person who has qualified both physically and psychologically/mentally for the education. Therefore, when 1 person of each force is expelled from education for any reason then it can be said that the institution has not succeeded in implementing the ideal education system.

The research that discusses about the SWAT application are research conducted by 
Rubio et al. the title Evaluation of Subjective Mental Workload: A Comparison of SWAT, Nasa TLX and Workload Profile. In that study, the results of the ANOVAs performed showed that there are no differences with regard to the three instruments' intrusiveness, and that among the three subjective workload instruments WP has an outstanding sensitivity to the different task manipulations (Rubio, et al., 2004).

Another research conducted by Widyanti et al that they adaptation of rating scale mental effort for use in Indonesia (Widyanti, et al., 2013). This study attempts to apply rsme searching task in experiments. 80 people were asked to fill in the questionnaires NASA TLX and RSME. And the result shows that RSME in line with NASA TLX.

Next research conducted by Waard about driving a vehicle, it may seem to be a fairly simple task (Waard, 1996). After some initial training many people are able to handle a car safely. Nevertheless, accidents do occur and the majority of these accidents can be attributed to human failure. At present there are factors that may even lead to increased human failure in traffic. So the author disscussed about measurement mental workload drivers.

In the study by Battiste and Bortolussi. This research was a part of study which investigated workload measures for aircraft certification. No significant main effects were found for any performance- based measures of workload. Both SWAT and NASA-TLX were sensitive to differences between high and low workload flights and to differences among flight segments (Battiste \& Bortolussi, 1988).

The Study of Sirevaag et al. This research see claims through the process of two places format different communication, digitally and verbal, in a simulated high and the higher multi-function helicopter (Sirevaag, et al., 2010). The discussed in terms of structural and capacity communication systems suit filed for the advancement of multi-function helicopter.

Some of these studies showed that the Subjective Workload Assessment Technique method could be used to analyze the level of mental workload in various fields (Eggemeier, et al., 1982) (Nygren, 1985).

Therefore, this study would identify one of the factors that were suspected to be the cause of the Cadets problem, namely psychological factors or mental workload in Cadets level I, level II, level III and level IV while undergoing education at Naval Academy using SWAT method. SWAT method was chosen because it was easier to apply and had several advantages in terms of validity and accuracy of the results, so that the performance of Cadets expected by the institution could be obtained, namely: Tanggap, Tanggon and Trengginas and at the same time could be a recommendation for the institution in taking policy.

\section{MATERIAL AND METHODS \\ 2.1 Workload}

Working loads experienced by a worker/employee are physical workload, mental and psychological workload arising from the work environment (Moray, 1982). Workload is designed in accordance with the capabilities and limitations of both physical and mental workers. Therefore, information on workloads obtained through measurement becomes important. The basic concept of mental workload leads to the difference between the processing resources available to the operator and the resource requirements needed in the task (Vidulich \& P.S.Tsang, 2007).

Basically, the workload explains the interaction between an operator performing the task and the task itself. In other words, the term workload illustrates the difference between the capacities of a human information processing system that is expected to satisfy the expected performance and that capacity is available for actual performance (Hancock \& N.Meshkati, 1988). Henry R. Jex defined the mental workload as "the operator's evaluation of the attentional load margin (between their motivated capacity and the current task demands) while achieving adequate task performance in a mission-relevant context" (Derrick \& Wickens, 1984).

\subsection{SWAT (Subjective Workload Assessment Technique)}

The SWAT Method (Subjective Workload Assessment Tehnique) is one of the way to measure the mental workload developed by Harry G. Armstrong, the Aerospace Medical Research Laboratory, Wright-Petterson Air Force Base, Ohio, USA to answer the question of how to measure mental workload in real environment (Real World Environtment) naturally and objectively from qualitative data sources (Reid \& Nygren, 1988). SWAT was divided into 2 steps (R.S.Bridger, 1995) namely:
Scale Development
In the scale development, 
subjects are required to conduct a card ordering of 27 (twenty seven) combination cards from the lowest workload sequence to the highest workload, according to the perceptions of each person.

b. Event Scoring

In the scoring event, the tried person (subject) is asked his SWAT rating from each task, then SWAT rating, calculated by using SWAT program inside the computer to know the workload score of each combination

Based on SWAT model, human work performances are divided into 3 workload dimensions, namely: Time Load $(T)$, Mental Effort Load (E), dan Psychological Stress Load (S) (Waard, 1996) (Moray, 1982).

a. Time Load (T)

The time load dimension depends on the availability of time and the ability to step over (overlap) in an activity. This is closely related to timeliness analysis which is the primary method to find out if the subject can complete the task within the specified time range. This time load consists of three rating categories: Low Time Load, Moderate Load, High Time Load. As for the understanding of each rating according to SWAT levels, it would be described below:

1) Low Time Load. It always has excess time. The interruption and work simultaneously (overlap) between activities never happened or rarely happened.

2) Moderate Time Load. It sometimes has excess time. The interruption and work simultaneously (overlap) between activities often happended.

3) High Time Load. It has no excess time. The interruption and work simultaneously (overlap) between activities often happened or always happened.

b. Mental Effort Load (E)

The mental effort load is an indicator of the mental needed and attention required to complete an activity, it was independent of the number of sub-jobs or time constraints (Jung \& Jung, 2001). With a low mental effort workload, the concentration and attention required to perform low activity and performance tend to be automated. As these loads increase, the concentration and attention required would also increase. In general, this is related to the level of complexity of work and the amount of information that must be processed by the subject to carry out his work well.

High mental effort requires overall concentration and attention according to the complexity of the work or the amount of information to be processed (Sekker, 2014). Activities such as calculation, decision making, remembering information and problem solving are examples of mental effort. Mental effort load consists of three categories of rating : Low Mental Effort Load, Moderate Mental Effort Load, High Mental Effor Load (YM \& ZM, 2005). As for the meaning of each rating according to SWAT levels, it would be described bellow:

1) Low Mental Effort Load. The need for concentration and conscious mental effort is very small. Activities performed almost automatically and do not need attention.

2) Moderate Mental Effort Load. Concentration needs and moderate conscious mental effort. The complexity of moderate to high activity is consistent with uncertainty, predictive disability, and unfamiliarity. Additional attention is required.

3) High Mental Effort Load. The need for concentration and conscious mental effort is enormous. Job activities are so complex that they require more attention.

c. Psychological Stress Load (S)

The workload of psychological distress relates to conditions that can lead to confusion, frustration, and fear during work, thereby causing work resolution to be more difficult than it really is (Sirevaag, et al., 2010).

People tend to relax at low stress level. Along with the increase of stress, there is confusion concentration to the relevant aspects of a job that is more caused by individual factors of the subject. These factors include: motivation, fatigue, fear, skill level, temperature, noise, vibration, and comfort. Most of these factors affect the performance of the subject directly if they arrive at a high level. Albeit small, 
these factors woulb be taken into account in SWAT if it interferes and causes the individual to exclude his ability to prevent the job from being affected (Sheridan, 1980).

Psychological Pressure Load consists of three rating categories: Low Psychological Pressure Load, Moderate Psychological Pressure Load and High Psychological Pressure Load. As for the meaning of each rating according to SWAT levels, it would be described below (Eggemeier \& Stadler, 1984):

1) Low Psychological Load. Confusion, risk, frustration or anxiety can be overcome easily.

2) Moderate Psychological Load. The stress that arises and deals with confusion, frustration and anxiety adds to the existing workload. Additional compositions are necessary to maintain the performance of the subjects.

3) High Psychological Load. There is high stress associated with confusion, frustration and anxiety. At this level, it requires great self-control.

Each of these dimensions consists of three rating categories with workload intervals as follows (Sirevaag, et al., 2010) (Luximon \& Goonetilleke, 2001) :

1) Lower Load if the final scale is $0-40$

2) Medium Load if the final scale is $41-60$

3) Over Load if the final scale is $61-100$

\subsection{Methodology}

This research was qualitative research where the data was taken directly from the respondents which was Cadets by distributing 27 SWAT cards to be sorted starting from the lowest and highest mental workload and filling in the questionnaire related to Education at Naval Academy 2012/2013. The sampling method was taken randomly. The samples required for the adequacy of the data in this study were as many as 120 samples, consisting of 30 people in Level IV, 30 people of Level III, 30 people of Level II 30 people of Level I. It was obtained with experiment design with anova nested anova method without interaction.

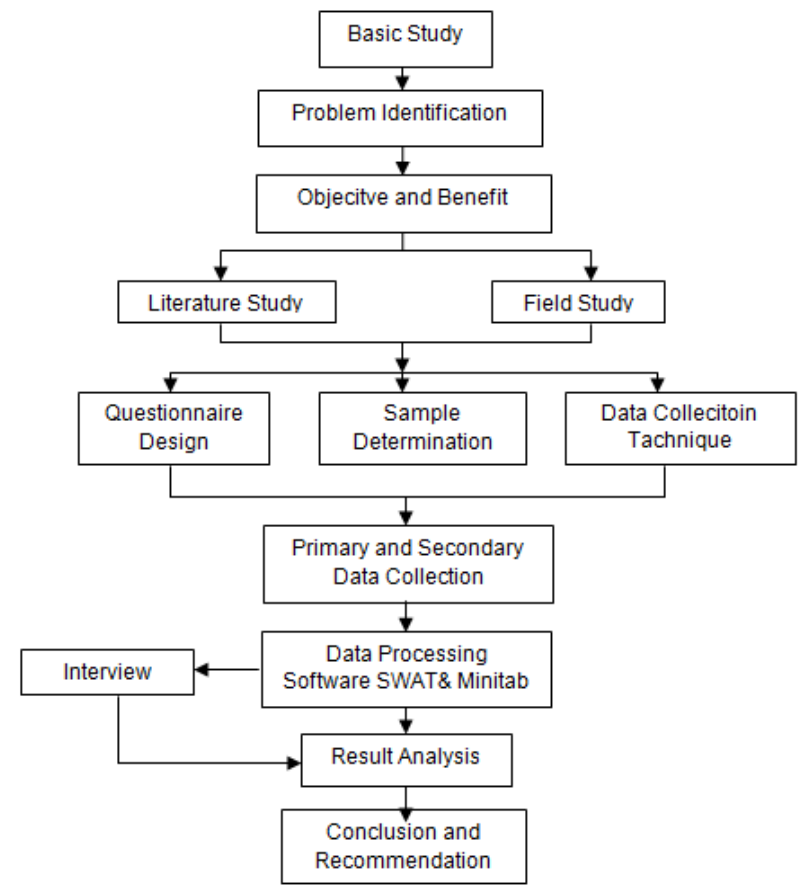

Fig. 1 Research Process Steps/flowchart

\subsection{Data Collection}

The data collection using SWAT method was by scale development. The Cadets was asked to sort the cards of 27 combined cards from the lowest workload sequence to the highest workload based on correspondent (Cadet)'s perspective. In the ordering of the card, there is no rule which was right or wrong. The ordering of cards was done according to the perceptions of each correspondent. In addition to sorting 27 SWAT cards, Cadets filled out a questionnaire about the workload of the activities it undertook. In the questionnaire, cadets were also asked to rate the workload experienced by the activities.

\subsection{Data Processing}

After collecting data from 27 SWAT cards according to the order from the lowest to the highest based to the perception of each correspondent, then the results of this card sorting were recorded and downloaded on the computer to interpret the dimension scale into the SWAT (Scaling Solution) scale. In addition, the results of filling out questionnaires on activities carried out by Cadets were transformed into Event Scoring. From the result of conversion between SWAT scale to SWAT rating, the work load of each Cadets could be known.

Finally, to test and compare the mental workload of the four levels with each of the 30 Cadets Per levels and 4 activities with 25 sub- 
activities performed, the Nested Anova test was used with the help of Minitab 16 software.

\section{RESULT AND DISCUSSION}

In this study Cadets was asked to provide an assessment of the workload consisting of time load $(T)$, mental effort load (E) and psychological pressure load (S). The activities of Cadets divided into 4 groups. The group activities were: routine activities, parenting activities, teaching activities and training activities as shown in Table 1.

Table.1 The Cadet's Activity Group

\begin{tabular}{|c|c|l|}
\hline Activities & No & \\
\hline Routine & 1 & Waking Up \\
& 2 & Morning Training \\
& 3 & Breakfast \\
& 4 & Morning Roll Call \\
& 5 & Noon Roll Call \\
& 6 & Lunch \\
& 7 & Dinner \\
& 8 & Evening Study Session \\
& 9 & Evening Roll CAll \\
\hline Nurturing & 10 & Ceremony \\
& 11 & Exercise \\
& 12 & Inspection \\
& 13 & Karate \\
\hline Teaching & 14 & Physical Training \\
& 15 & Proffesion Learning \\
& 16 & Non-profession Learning \\
& 17 & Examination \\
& 18 & Military Gymnastic \\
& 19 & Basic Military Rule \\
& 20 & Agile Field \\
& 21 & Military Fighting \\
& 22 & Military Swimming \\
& 23 & RPS \\
& 24 & Fielding, Maping, and Compass Knowledge \\
& 25 & Grenades Throwing \\
\hline
\end{tabular}

\subsection{Card Arranging Analysis and Scale Development}

Based on the data processing, if Kendall coefficient showed value more than 0.75 then the scale that could be used here was group scaling solution). This groups were described as follows :
a. Level IV of Cadets
After the data processing was performed, the coefficient of kendall could be obtained and it was 0,9730 as shown in Figure 2 Cadets Level IV prefered time factor in completing each job, in addition to having a high effort workload (effort), while for the business of stress (stress) in this group was not really needed. The relative importance of each factor was $68.50 \%$, the time factor indicating that the Level IV tuna collectively prefers the time factor $(T)$. The second factor was the Mental Effort (E) with a percentage of $21.77 \%$ and the last dimension was the dimension of Stress (S) with a percentage of $9.73 \%$.

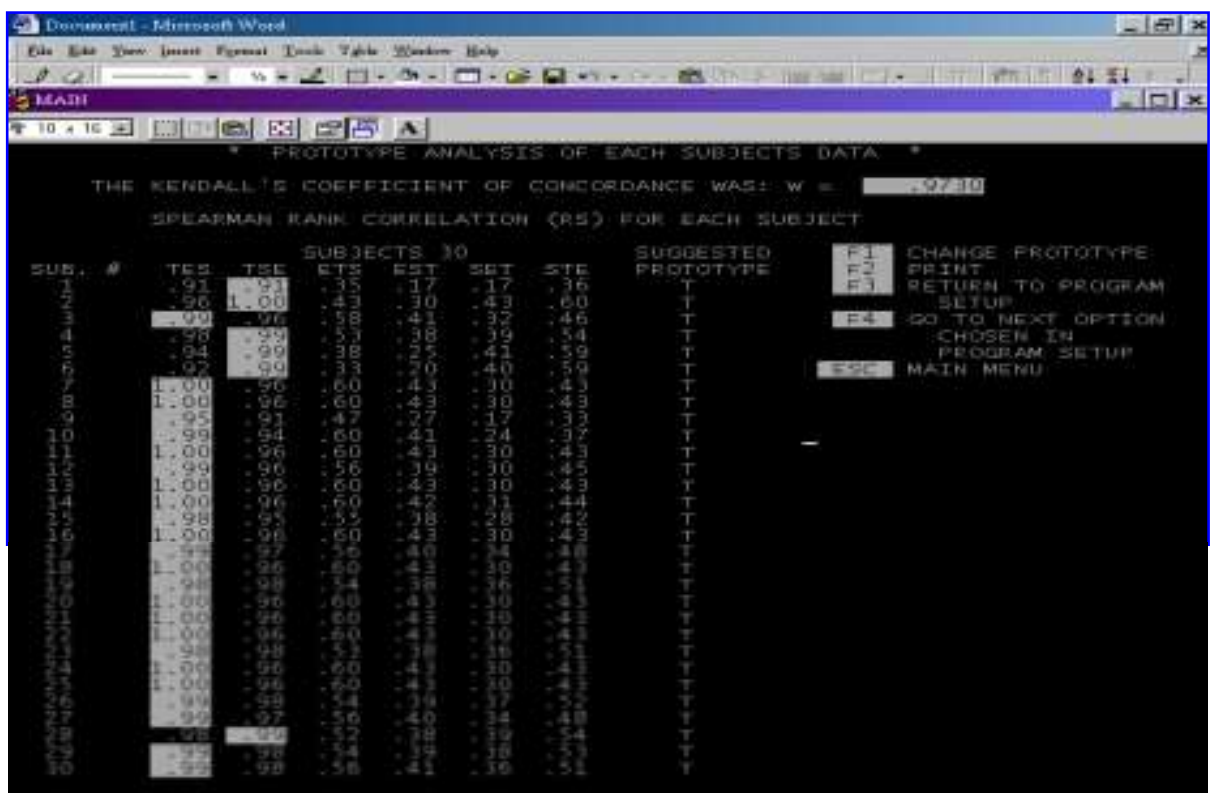

Fig. 2 Result Kendal's Coefficient Level IV of Cadets 
b. Level III of Cadets

The kendall coefficient value was obtained at 0.9867 as shown in Figure 3 . Cadets Level III prefered the time factor in completing each job, in addition to having a similar amount of mental effort and stress workload. The relative importance of each factor was $67.50 \%$. The time factor indicating that Level III collectively prefered the time factor $(T)$. The second factor was the mental effort dimension factor (E) with the percentage of $20.00 \%$ and the last dimension was stress (S) with a percentage of $12.50 \%$.

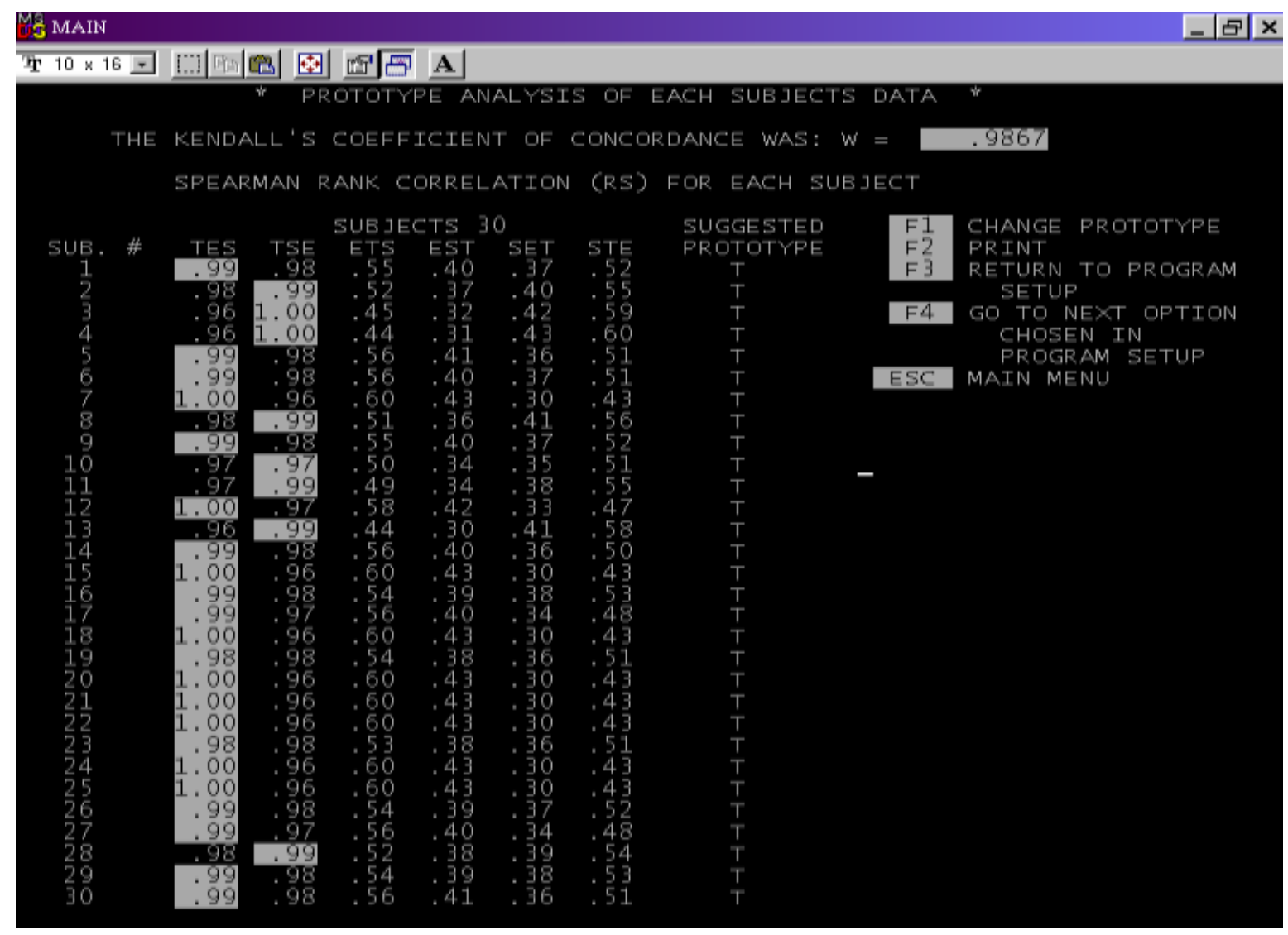

Fig. 3 Result Kendal's Coefficient Level III of Cadets

c. Level II of Cadets

The kendall coefficient value was obtained at 0.9693 as shown in Figure 4. Cadets Level II prefered the time factor in completing each job, in addition to have a high stress workload yet low mental effort load. The relative importance of each factor was $68.50 \%$. The time factor indicating that Level II collectively prefered the time factor (T). The second factor was the mental effort dimension factor $(E)$ with the percentage of $21.78 \%$ and the last dimension was stress (S) with a percentage of $9.73 \%$. 


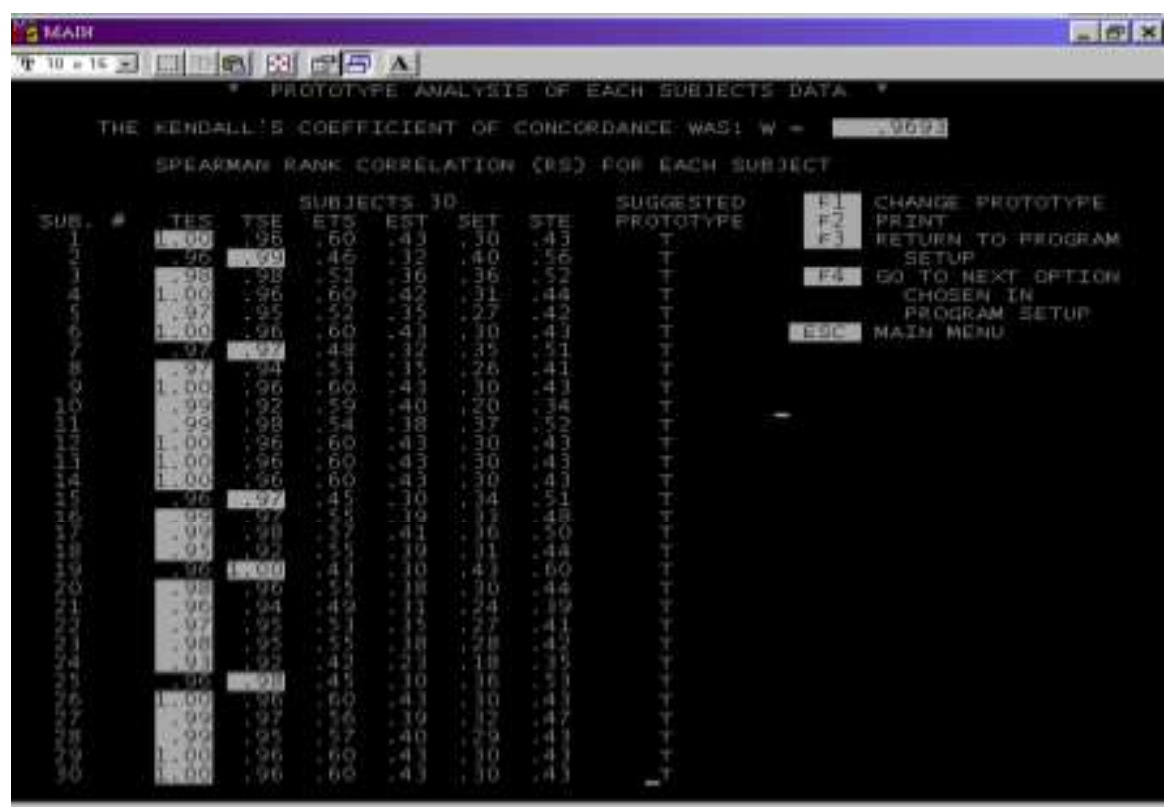

Fig. 4 Result Kendal's Coefficient Level III of Cadets

d. Level I of Cadets

The kendall coefficient value was obtained at 0.9809 as shown in Figure 5. Cadets Level I prefered the time factor in completing each job, in addition to having a similar amount of mental effort and stress workload. The relative importance of each factor was $67.50 \%$. The time factor indicating that Level I collectively prefered the time factor $(T)$. The second factor was the mental effort dimension factor (E) with the percentage of $18.10 \%$ and the last dimension was stress (S) with a percentage of $14.10 \%$.

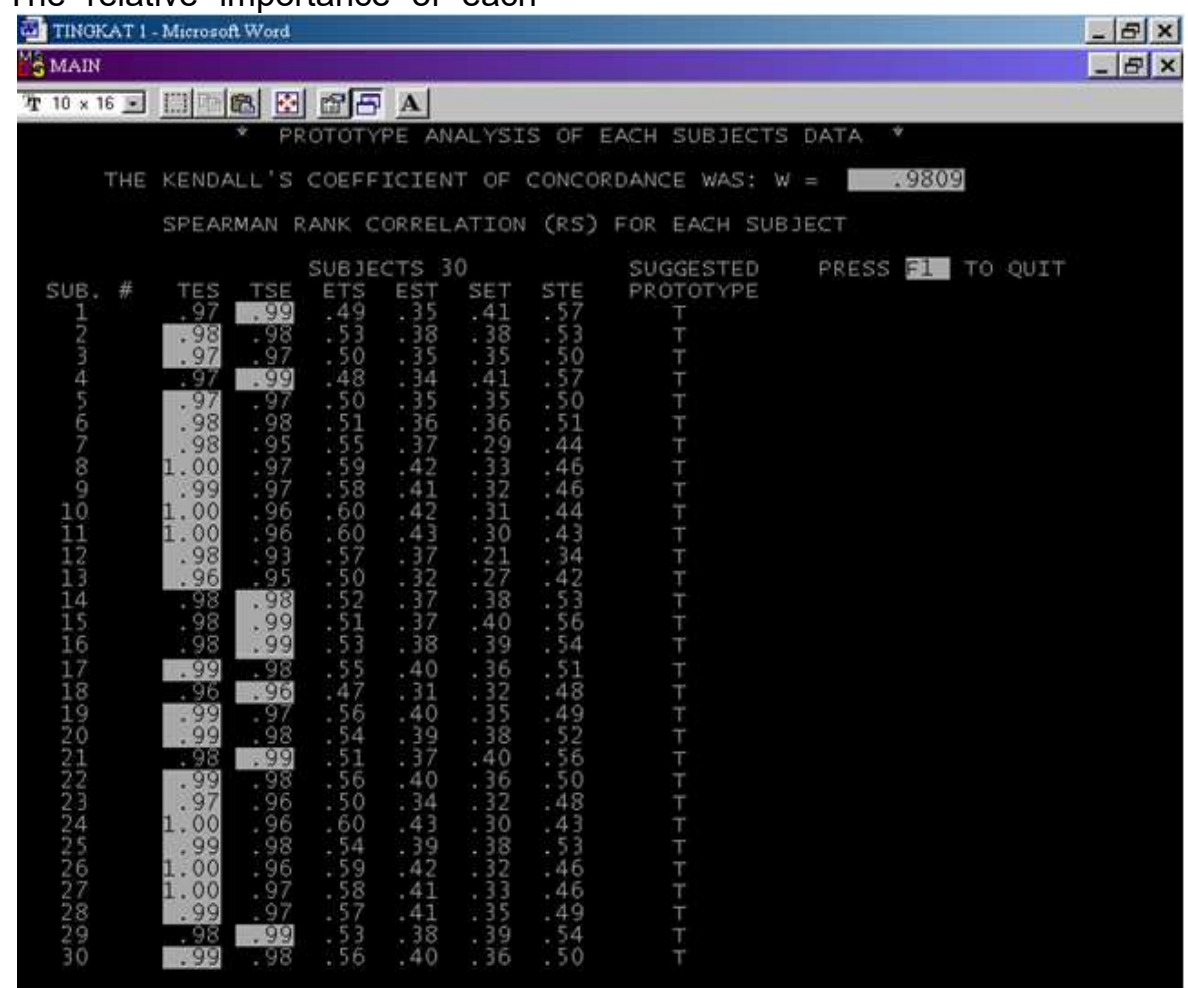

Fig. 5 Result Kendal's Coefficient Level III of Cadets

Based on the data processing, it could be seen that each level of Level IV, Level III, Level II and Level I indicated group-based data processing, which was indicated from the acquisition of the 
coefficient of kendall. The results of group-based data processing showed that it was related to the pattern of life in the military. Military life had a tendency to always be in groups and always maintain the group, ranging from groups of squads, platoon, company, batalioon up to the Brigade or the army.

\subsection{Respective Workload Analysis on Activity in Each Level}

In each level there are many activity and average level as shown in Table 2.

Table. 2 Result of each activity and average level

\begin{tabular}{|c|c|c|c|c|c|c|c|c|}
\hline NO & $\begin{array}{c}\text { SUB } \\
\text { ACTIVIIIES LEV I }\end{array}$ & $\begin{array}{l}\text { AVERAGE } \\
\text { LEVEL I } \\
\end{array}$ & $\begin{array}{c}\text { SUB } \\
\text { ACTIVITIES LEV II }\end{array}$ & $\begin{array}{l}\text { AVERAGE } \\
\text { LEVEL II }\end{array}$ & $\begin{array}{c}\text { SUB } \\
\text { ACTIVTIES LEVIII }\end{array}$ & $\begin{array}{l}\text { AVERAGE } \\
\text { IFVEL III } \\
\end{array}$ & $\begin{array}{c}\text { SUB } \\
\text { ACTIVITIES LEVIV }\end{array}$ & $\begin{array}{l}\text { AVERAGE } \\
\text { IEVEL N } \\
\end{array}$ \\
\hline 1 & Wakng up & 26,5 & Waking Up & 57,8 & Waking Up & 54,2 & Waking Up & 42,3 \\
\hline 2 & Morning Tra ining & 26,4 & Mornng Tra ining & 59,9 & Mo ming Trainng & 50,6 & Noming Trainng & 36,6 \\
\hline 3 & Breaktast & 15,1 & B reaktast & 61,5 & Breakfast & 46,4 & Breaktast & 16,0 \\
\hline 4 & Morning Foll Call & 25,3 & Mornng Foll Call & 58,2 & Noming Roll Call & 53,1 & Noming Foll CaI & 19,0 \\
\hline 5 & Noon Foll Call & 51,5 & Noon Foll Call & 70,8 & Noon Fol Call & 44,3 & Noon Foll Call & 12,7 \\
\hline 6 & Lunch & 45,1 & Lunch & 75,1 & Lunch & 63,6 & Lunch & 8,6 \\
\hline 7 & Dinner & 28,8 & Dinner & 64,4 & Dinner & 38,2 & Dhner & 8,0 \\
\hline 8 & Eveningstudy & 29,6 & Evenng Study & 43,2 & Evening Study & 22,5 & Evening Study & 8,6 \\
\hline 9 & Evening Foll Call & 56,0 & Evenng Foll Call & 82,6 & Evening Foll Call & 52,3 & Evening Foll CaI & 4,5 \\
\hline 10 & Ceremony & 38,0 & tra ditiona I Foll Call & 82,6 & trad rional Foll Call & 69,8 & trad mional Foll Call & 5,9 \\
\hline 11 & Exerclse & 32,2 & Exerclse Roll Call & 47,2 & Exerclse Foll Call & 36,6 & Exerclse Foll Call & 10,6 \\
\hline 12 & In spection & 34,9 & Exerclse time & 43,8 & Exerclse time & 30,2 & Exerclise time & 12,4 \\
\hline 13 & Ka rate & 37,8 & GS Training & 81,4 & GS Training & 76,3 & GS Training & 17,8 \\
\hline 14 & Phsylcal Traning & 42,9 & Karate & 55,4 & Karate & 29,1 & Karate & 8,0 \\
\hline 15 & Promeson Learning & 26,1 & On Duty & 67,2 & On Duty & 51,3 & On Duty & 21,6 \\
\hline 16 & Non-Prome sion Lean & 32,9 & Sen br ynilor develo pme & 83,4 & Senlor junlor developt & 77,6 & Senlor jun lor deve lop & 5,4 \\
\hline 17 & Examination & 41,1 & Pryy slcal Training & 63,6 & Physlcal Trainng & 56,4 & Physcal Trainhg & 50,0 \\
\hline 18 & Miltary Gym & 41,1 & Protession learnh & 44,6 & Profession leaming & 53,5 & Profession learning & 27,1 \\
\hline 19 & Baslc MItrary Fule & 34,5 & Non-Promesion Lean & 36,9 & Non Protresion Learn & 19,0 & Non P r mesion Learn & 8,5 \\
\hline 20 & Aglle Fle id & 53,0 & Theory Exam & 50,7 & Theory Exam & 44,3 & Theory Exam & 38,5 \\
\hline 21 & Miltary Fighting & 38,3 & Practical Exam & 49,5 & Practical Exam & 56,8 & Practical Exam & 31,9 \\
\hline 22 & Miltary Swimmng & 36,3 & Ja lase sy a sa ling & 47,8 & Shoothg & 24,5 & Jala Yuda & 35,9 \\
\hline 23 & FPS & 69,0 & Sea sunvival & 45,7 & Scuba & 43,7 & Sw inming & 17,4 \\
\hline 24 & Mapping n Compass & 54,2 & PekNublka & 44,4 & Latek Protesl & 53,1 & Latsita rdanus & 3,7 \\
\hline 25 & Grenades Throw ing & 41,0 & Swimmng & 55,5 & Sw imming & 54,6 & Profesional Training & 16,3 \\
\hline
\end{tabular}

At this analysis stage, the sub activities that would be discussed on each level had SWAT score above 61 (61-100). According to SWAT method, it was considered as high load work category (high load). If we see in Figure 6 Level IV there wasn't any high mental workload. Based on Interviews with some respondents, Cadets level IV and Cadet's Mentoring, it was found that it was due to the the state of Cadets level IV. Cadets level IV was the most senior Cadets at the Academy so that in the implementation of activities, they could carry out well without pressure from anywhere. 


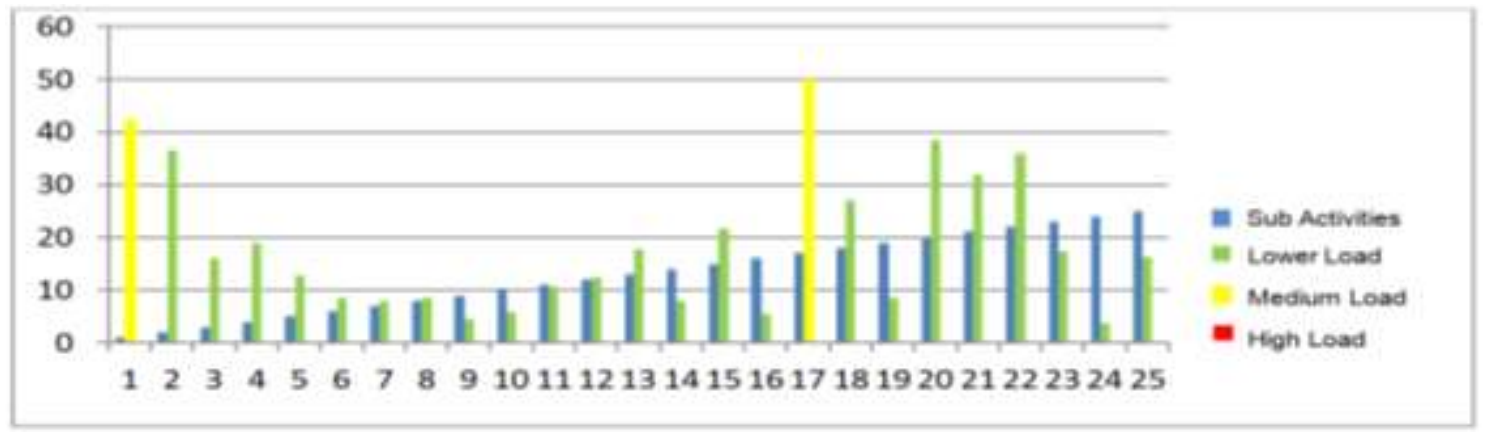

Fig. 6 Graph of Level IV Cadets Based on SWAT Scale

In Figure 7 the Level III of Cadets group, there were several sub activities that had a high mental workload, from 25 sub activities there were 4 sub-activities included in the category of high mental workload. The sub activities would be described bellow:

a. Lunch

Lunch was held jointly between level II, III, and IV in one table, lunch started at 12:45 to 13:00. This sub activity had mental load average of 63,3 which according to SWAT included in high load category.

b. Traditional Roll Call

It was the Cadets Corp Regiment Assembly which was held on Saturday Morning. This activity was taken over by Cadets Corps officials. It was held at 07.00-finish, the mental workload on this sub activity was 69.8. In this activity the junior Cadets will be checked for the neatness of personnel and material, ranging from shoe, clothes, hair neatness and others. If there were deficiencies or violation, they would get disciplinary punishment.

c. Drum Flute Training(GS)

Drum Band Training was held 3 times a week in the morning and evening. The value of mental workload on this activity was equal to 76.3. This was because the level of difficulty and compactness in training was high enough to force them to practice hard, along with the pressure of senior Cadets punishment in case of errors in the exercise so that the mental workload of the Cadets was higher.

d. Senior Junior Development

This activity was anything related to senior Cadets coached against junior Cadets about the life of the Cadets Corps Regiment. Senior were allowed to impose a proportional penalty against any wrongdoing by junior Cadets.

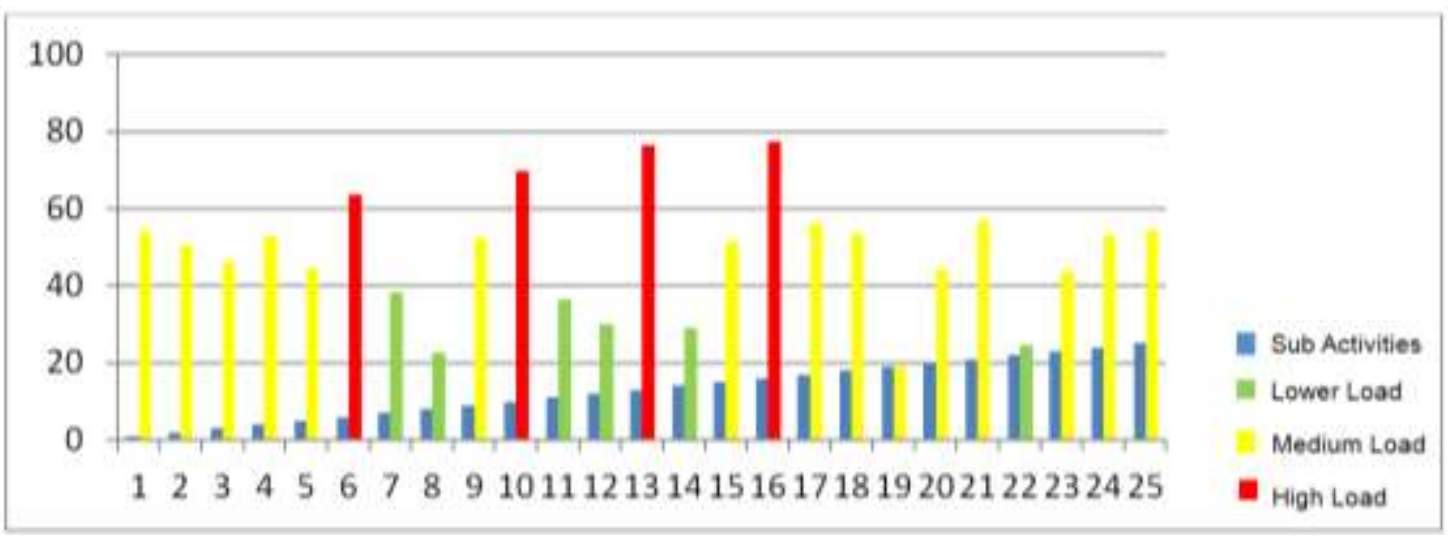

Fig. 7 Graph of Level III Cadets Based on SWAT Scale 


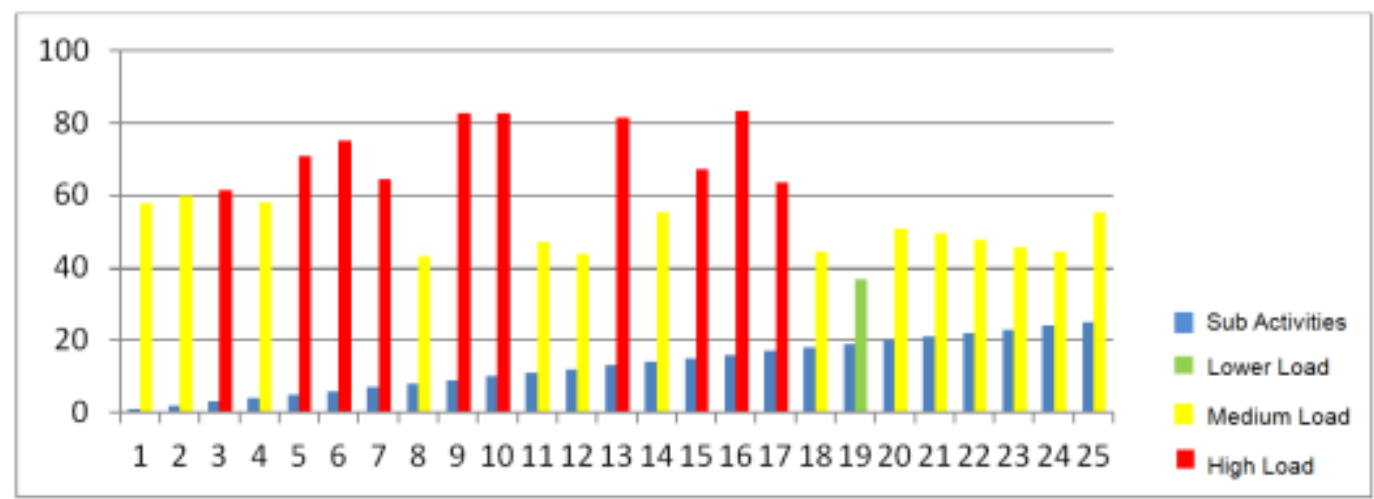

Fig. 8 Graph of Level II Cadets Based on SWAT Scale

Based on the graphic figure 8 of Load Workload Level II, there were some sub activities that had a high mental workload, from 25 sub activities there were 10 sub-activities included in the category of high mental workload. The sub activities were described bellow:

a. Breakfast with an average mental load value of 61.5 .

b. Noon Roll Call with an average mental load value of 70.8 .

c. Lunch with an average mental load score of 75.1

d. Dinner with an average mental workload of 64.3. e. Night Roll Call with an average mental load value of 82.6.

f. Tradition Roll Call with an average mental load value of 69.8 .

g. Drum Flute Training (GS) with an average mental load value of 81.4 .

h. On Duty with an average mental load value of 67.2 .

i. Senior Junior Development with an average mental load score of 83.3.

j. Physical Training with the average mental load value of 63.6 ,

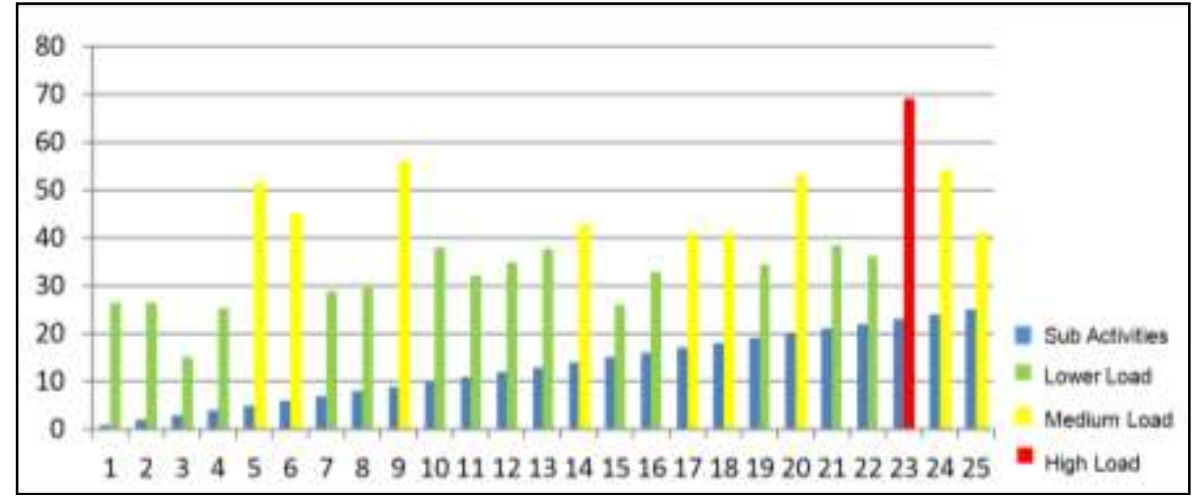

Fig. 9 Graph of Level I Cadets Based on SWAT Scale.

In Figure 9, the Level I Cadets, there were several sub activities that had high mental workload. From 25 sub activities, there wass only 1 sub activity that included in the category of high mental workload. That sub activity was Route Commander Soedirman (RPS). It was a Long March activity to commemorate the Commander Soedirman's struggling for independence. The distance traveled was long and hard so that the Cadets Level I felt burdened with this sub-activity. Other than that, the weather at that time was bad and made their shoes wet and sore, also they had to carry the goods in a bag of hinges that contains logistics inventory for 3 days. It made their burden getting heavy. Some respondents also said that the lack of exercise factor was also the cause of the weight in this activity. The mean mental load of this activity was 69.0

\subsection{Data Test Analysis with ANOVA}

Anova testing was intended to test the uniformity of the population and compare it. The population was consisted of Level I, Level II, Level III, and Level IV. The thing that we wanted to know 
was whether there was a significant difference in the mental workload between the four levels and the significant differences in each activity.

The results of the test with Nested anova showed that the four levels of Level I, Level II, Level III, and Level IV Cadets had a significant difference in mental workload between each other, as well as the activities performed. There was a very significant difference in each activity at each level. This was in accordance with the initial hypothesis that there wass indeed a difference between the 4 (four) levels and the activities.

\subsection{Recommendation}

Based on observations, interviews and data analysis, the recommendations could be given to activities which had been considered having a high workload so that expectations of these activities could run well without changing the essence of the activity itself. Here were suggestions for improving sub activities.

$\begin{array}{ll}\text { a. Dine Activity } & \\ \text { The } & \text { supervision of Officers and }\end{array}$ Commisioned Officer must be further tightened to avoid the disproportionate actions or penalties from the senior Cadets to the junior in the dining room. Disciplinary punishment must be performed to the senior Cadets who was caught performing dishonest acts in the dining room.

b. Traditional Roll Call

The seniors should set a good example for the junior Cadets and need proper supervision from the Commisioned Officer to avoid the disproportionate actions of the senior to the Junior Cadets.

c. Genderang Suling Training (GS)

It was necessary to teach theories about musical instruments by music experts, so that when exercised the Cadets understand with the musical instrument he holds, this was to avoid mistakes in the practice that led to more penalties than the exercise itself. Although at the time the fully responsible practice was the GS Caregiver, but other caregivers should keep an eye on the exercise.

d. Senior-Junior Development

The need for supervision of all activities in buildings and rooms and the provision of disciplinary punishments provided by senior Cadets should be educational and not excessive.

\section{CONCLUSION}

4.1. In general, based on the interviews, observations and in-depth analysis, the mental workload of Level IV Cadets did not contain a high mental workload as they are the most senior Cadets in the Academy. They do not feel pressured in carrying out any activities. As for Level III, they had a high workload in four activities: Lunch $(63,6)$, traditional Roll Call $(69,8)$, GS Training $(76,3)$ and Senior Junior Development $(77,6)$. Meanwhile, while Level II Cadets had more mental workload among these activities: Breakfast $(61,5)$, Lunch $(70,8)$, Noon Roll Call $(70,8)$, Lunch $(75,1)$, Dinner $(64,4)$, Evening Roll Call $(82,6)$, Traditional Roll Call $(82,6)$, GS Training $(81,4)$, Duty $(67,2)$, Senior Junior Development $(83,4)$, and Physical Training $(63,6)$. Finally, the activity with the most mental workload for Level I was RPS (Rute Panglima Sudirman /Panglima Sudirman Route) which is score is 69,0 ..

4.2. The result of ANOVA test showed that the four level workloads that were Level IV, Level III, Level II and Level I were not identical. It means that there wes a very significant difference between each level as well as all of the activities that had been performed. Anova testing results showed that the four activities had a very significant difference.

4.3. Most Cadets Juniors had a high mental workload due to the pressures of the senior Cadets, this was ilustrated in the results of the data. The smaller the level the greater the mental workload was perceived. However, this condition did not occur in Level I Cadets because they were in Magelang and not directly related to their senior. It means that the senior-junior direct interaction in the Academy greatly affected the mental workload for the Cadets, especially the Junior Cadets.

\section{ACKNOWLEDGEMENT}

The authors greatly acknowledge the support from Sekolah Tinggi Manajemen STIMA IMMI Jakarta Indonesia for providing necessary resources to carry out this research work. The authors are also grateful to the anonymous reviewers and journal editorial board for their many insightful comments, which have significantly improved this article.

\section{REFERENCES}

Battiste, V. \& Bortolussi, M., 1988. Transport pilot workload: A comparison of two subjective techniques.. Santa Monica, Human Factor Society.

Derrick, W. \& Wickens, C., 1984. A multiple processing resource explanation of the subjective dimensions of operator workload. Champaign: Univercity of Illinois, Engineering Psychology Laboratory. 
Eggemeier, F., Crabtree, M. \& Reid, G., 1982. Subjective workload assessment in a memory update task. Santa Monica, Human Factor Society.

Eggemeier, F. \& Stadler, M., 1984. Subjective workload assessment in a spatial memory task. Santa Monica, Human Factor Society.

HAncock \& N.Meshkati, 1988. Human Mental Workload. New York: North Holland.

Jung, H. S. \& Jung, h. S., 2001. Establishment of overall Workload Assessment Technique for Various Tasks and Workplaces. International Journal of Industrial Ergonomics, 28(6), pp. 341-353.

Luximon, A. \& Goonetilleke, R. S., 2001. Simplified subjective workload assessment technique. Ergonomics, 44(3), pp. 229-243.

Moray, N., 1982. Subjective mental workload. Human Factors, Volume 24, pp. 25-40.

Nygren, T., 1985a. Axiomatic and numeric conjoint measurement: A comparison of three methods for obtaining subjective workload (SWAT) rankings. New York, Institute of Electrical and Electronics Engineers.

R.S.Bridger, 1995. Introduction to Ergonomics. Singapura: McGraw-Hill.

Reid, G. B. \& Nygren, T. E., 1988. The Subjective Workload Assessment Technique : A Scalling Procedure for Measuring Mental Workload. Advances in Psychology, Volume 52, pp. 185-218.

Rubio, S., Diaz, E., Martin, J. \& Puente, J. M., 2004. Evaluation of Subjective Mental Workload: A Comparison of SWAT, NASA TLX and Workload Profile Methods. Applied Psychology, 53(1), pp. 6186.
Sekker, A., 2014. Using Outputs of Nasa TLX for buiding a mental workload expert system. Journal of Science, 27(4), pp. 1131-1142.

Sheridan, T., 1980. Mental workload-What is it? Why bother with it?. Human Factor Society Bulletin, 23(2), pp. 1-2.

Sirevaag, E. J. et al., 2010. Assessment of Pilot Performance and mental Workload in Rotary Wing Aircraft. Ergonomics, Volume 36, pp. 1121-1140.

Vidulich, M. \& P.S.Tsang, 2007. Techniques of subjective workload assessment : a comparison of SWAT and the NASA-Bipolar methods. Ergonomics, Volume 29, pp. 1385-1398.

W.Masland, J. \& Radway, L. I., 2015. Soldiers and Scholars : Military Education and National Policy. s.l.:Princeton University Press.

Waard, D. d., 1996. The measurement of Drivers Mental Workload. Netherlands: The Traffic Research Centre VSC, Univercity og Groningen.

Widyanti, A., Jhonson, A. \& Waard, D. D., 2013. Adaptation of Rating Scale Mental Effort for use in Indonesia. International Journal of Industrial Ergonomics, Volume 43, pp. 70-76.

YM, X. \& ZM, W., 2005. The Appraisal of Reliability and Validity of Subjective Workload Assessment Technique and NASA-task load index. Europe PMC, 23(3), pp. 178-181.

Yudhoyono, A. \& Jalal, m. A., 2009/2010. Stronger Militaries through the Transformation of Military Education. Kennedy School Review Cambridge, Volume 10, pp. 109-113. 